\title{
International Spinal Cord Society (ISCOS) database: Asian Spinal Cord Network (ASCoN) Pilot Project [IDAPP]
}

\author{
H. S. Chhabra ${ }^{1}$ - G. Sachdeva ${ }^{1}$ A. Kovindha ${ }^{2}$ - M. S. Hossain ${ }^{3}$ N. Hasnan ${ }^{4}$ - E. Thapa ${ }^{5}$ - S. Rajasekaran ${ }^{6}$. \\ M. Y. Yusniza ${ }^{7}$ S. Sybil Shah ${ }^{8}$ - N. Pinto ${ }^{9}$. C. Groves ${ }^{5,10}$ - P. Kammuang-lue ${ }^{2}$ - S. U. Helal ${ }^{3}$ - A. Ahmad Fauzi ${ }^{4}$. \\ S. Aiyer ${ }^{6} \cdot$ N. B. Ahmad Kasah ${ }^{7}$ R. A. C. Niroshanie ${ }^{9}$
}

Received: 7 November 2017 / Revised: 17 February 2018 / Accepted: 11 April 2018

(C) International Spinal Cord Society 2018

\begin{abstract}
Study design Global mapping project of ISCoS for traumatic spinal cord injury (T-SCI) highlighted paucity of data from low and middle income countries (LMICs). Recognizing this gap, IDAPP study of one year duration was proposed as the first step to develop an International SCI database.

Objectives Primary objective was to assess database variables, processes involved and web platform for their suitability with a view to provide guidance for a large scale global project. Secondary objective was to capture demographic and selected injury/safety data on patients with T-SCI with a view to formulate prevention strategies.

Setting Nine centers from Asia.

Methods All patients with T-SCI admitted for first time were included. International SCI Core Data Set and especially compiled Minimal Safety Data Set were used as data elements. Questionnaire was used for feedback from centers.

Results Results showed relevance and appropriateness of processes, data variables and web platform of the study. Ease of entering and retrieval of data from web platform was confirmed. Cost of one year IDAPP study was USD 7780. 975 patients were enrolled. $790(81 \%)$ were males. High falls $(n=513,52 \%)$ as a cause and complete injuries $(n=547,56 \%)$ were more common. There was a higher percentage of thoracic and lumbar injuries $(n=516,53 \%)$.

Conclusions The study confirms that establishing the SCI database is possible using the variables, processes and web platform of the pilot study. It also provides a low cost solution. Expansion to other centers/regions and including nontraumatic SCI would be the next step forward.
\end{abstract}

These authors contributed equally: H. S. Chhabra, G. Sachdeva, A. Kovindha A, M. S. Hossain, N. Hasnan, E. Thapa, S. Rajasekaran, M. Y. Yusniza, S. Sybil Shah, N. Pinto, C. Groves.

Electronic supplementary material The online version of this article (https://doi.org/10.1038/s41394-018-0076-5) contains supplementary material, which is available to authorized users.

\footnotetext{
H. S. Chhabra

issicon@isiconline.org

Indian Spinal Injuries Centre, New Delhi, India

2 Chiang Mai University, Chiang Mai, Thailand

3 Centre for the Rehabilitation of the Paralysed, Dhaka, Bangladesh

4 University of Malaya, Kuala Lumpur, Malaysia
}

\section{Introduction}

Spinal cord injury (SCI) is a medically complex condition historically associated with very high mortality rates in the past. Life expectancy of persons with SCI in low and middle income countries (LMICs) is shorter compared to general population in their countries as well as to persons with SCI in high income countries (HICs) [1]. There is a wide variance in the prognosis of persons with SCI based on the prevailing socioeconomic conditions in different

\footnotetext{
Ganga Spine Injury Rehabilitation Centre, Coimbatore, India

Queen Elizabeth Hospital, Sabah, Malaysia

7 National Hospital of Sri Lanka, Colombo, Sri Lanka

8 Spinal Injury Rehabilitation Centre, Kavre, Nepal

9 Indiana University School of Medicine, Indiana, USA

10 Cheras Rehabilitation Hospital, Kuala Lumpur, Malaysia
} 
countries. In HICs, SCI is considered a social challenge with a successful outcome defined as a near normal and productive life. In low-income countries, SCI remains a frequently terminal condition, with limited availability of services and resources, as well as reduced opportunities for meaningful community reintegration [2]. The cost for a person with SCI in US can range from $\$ 334,000$ to 1 million in the first year of injury. In the subsequent years the cost can range from $\$ 41,000$ to 178,000 based on the severity of injury [3]. Though exact financial burden only due to SCI is not available for LMICs, World Health Organization (WHO) in one of its guidance document has estimated that Road Traffic Crashes (RTCs) costs between $1 \%$ and $1.5 \%$ of gross national product in LMICs [4]. In India too, studies have estimated the cost of injuries as between 0.29 and $0.69 \%$ of Gross Domestic Product of India [5]. Persons with SCI suffer from increased financial burden and a decline in the support system. Poverty generates barriers for persons with SCI and also deteriorates their medical conditions including increased risk of pressure ulcers and infections predisposing to premature death [1].

Steps to improve care and quality of life for persons with SCI must go hand in hand with measures to prevent SCI. To understand the socioeconomic impact of SCI, the epidemiology of SCI is a requisite. This should include both the prevalence and incidence of SCI, along with information regarding etiology of SCI.

The ISCoS global mapping project for traumatic SCI (T$\mathrm{SCI}$ ) brought out the paucity of data from less and leastdeveloped countries [6]. Moreover, the quality of data was also a major issue in all countries where SCI data was available. Hence, an urgent need was felt to facilitate high quality SCI-related data collection. Recognizing this need, the IDAPP was proposed as the first step of a long-term international SCI database that would gradually incorporate more centers across countries where no such endeavor has been undertaken so far.

The primary objective of the IDAPP study was to assess the appropriateness of database variables as well as the processes and the quality, user friendliness as well as error rate of web platform with a view to provide guidance for a large scale global project.

The secondary objective of the study was to capture demographic and selected injury/safety data on T-SCI patients admitted to selected Asian Spinal Cord Network $(\mathrm{ASCoN})$ centers with a view to formulate prevention strategies.

\section{Methods}

\section{Participating centers}

Nine centers from India, Bangladesh, Sri Lanka, Nepal, Malaysia, and Thailand participated in the study.

\section{Study inclusion and exclusion criteria}

All patients with a T-SCI admitted for the first time after injury to any of the participating centers were included in the study. Patients readmitted to the centers were excluded from participating in the study. Patients with non-traumatic SCI were also excluded.

\section{Study design}

IDAPP study was planned for one year. Requirement of Informed Consent (IC) for participants was governed by the regulatory requirements of the Center. The Institute Ethics Committees (IEC) of all nine participating centers declared that obtaining informed consent of the participants was not required. The one-year timeline for each center commenced after the approval from the IEC. All centers were to enroll patients until they completed one year enrollment period. The enrollment of the study participant involved screening as per the inclusion and exclusion criteria of IDAPP and data collection.

There was no predefined sample size for the pilot study. The centers were supposed to enroll all patients admitted to their centers for the first time.

\section{Data elements}

Data elements for the IDAPP study were the International SCI Core Data Set [7] and the Minimal Safety Data Set. The International SCI Core Data Set had been devised to homogenize the collection and report the minimum information necessary to depict demographic and clinical information of persons with SCI [7]. Minimal Safety Data Set was specially compiled incorporating the relevant components of International Classification of External Causes of Injuries (ICECI) [8], to capture the epidemiological aspects of cause of individual SCI, with a view to help formulate prevention strategies. The data elements were compiled by the Advisory, Prevention and Scientific Committee members of ISCoS and finalized by PIs after a brainstorming workshop during an ASCoN meeting. The International SCI Core Data Set and the Minimal Safety Data Set used in the study are appended in Appendix 1a and $1 b$. 


\section{Organizational structure}

The IDAPP was conducted under the strategic direction and management of the Advisory Committee from ISCoS. The Advisory Committee was responsible for helping in conceptualization and commencement of the project as well as defining roles and responsibilities of all concerned. The Committee was supported through a Central IDAPP team based in New Delhi, India and a network of local IDAPP teams comprising of site investigators and their teams at participating centers. The central IDAPP team constituted of Principal Investigator, Manager-Projects, ManagerAdmin, Project Coordinator, and Project Monitor. The team was responsible for data management and data quality control through good clinical practices. The Principal Investigator was responsible for overall operations, data management and data quality control. The Manager-Projects was responsible for data management and training of both central and site teams. Manager-Admin was responsible for the communications (external), fund management and administration issues related to the project. The Scientific Committee, comprising of site investigators of the centers, was made responsible for the use and disclosure of data collected in the project.

\section{Data collection and management}

A web platform, capable of being enhanced for the subsequent larger database, was specially created for the study. Data collected on each patient at the site was entered into the electronic case record form (e-CRF) of the database. Quality processes were embedded in the database to prevent inadvertent entries. The e-CRFs for all patients were stored electronically as a central database. An authorized person collected data from the patient case file at each center. The local IDAPP site Investigator at each center was responsible for the scientific and ethical conduct of the IDAPP and ensured that the local IDAPP team adhered to the protocol and all other IDAPP documentation. The local IDAPP coordinator was responsible for patient recruitment, data collection and day-to-day IDAPP operations. The local IDAPP monitor ensured that the site team was fully trained for study purposes. The monitor verified all entries to the eCRF and compared them with the clinic/practice raw data (source document, case files etc.). Access to e-CRF in the database was provided to the local IDAPP team for data entry processes. A one day training workshop was conducted for the study team during an ASCoN meeting. The study team was also provided all the documents pertaining to the study including Protocol, Patient Information Sheet and Informed Consent Form, Screening and Enrollment Log, Site Delegation Form, Data Clarification Form, Data Sharing Agreement and Publication Policy. An online regular training was also conducted for the study team and the local IDAPP site investigator was responsible to ensure that site study team was fully trained to conduct the study. The Project Monitor conducted online quality check of the data for completeness and appropriateness. The Central IDAPP team could access the data of patients from all centers. The local IDAPP team could only access the data for patients from individual centers.

The local IDAPP center was responsible for maintaining patient confidentiality. Each patient's data was marked (in $\mathrm{e}-\mathrm{CRF}$ ) by a unique number. This unique number was system generated and identifiable for each center. All potential patient identifying information, including the name, initials and date of birth, remained with the local site investigators and was never entered into the database.

\section{Feedback from participating centers}

A Questionnaire (Part A and B) for Investigators of IDAPP study was circulated amongst the participating centers to get feedback on the relevance, appropriateness of study design, quality of documents, and issues faced by the site study teams while conducting the IDAPP study. Part A of the questionnaire included questions on the quality and appropriateness of the study and was scored between 1 and 10 with 10 implying the best score. Part B dealt with the problems faced at individual sites while performing the activities related to the IDAPP study and was scored between 1 and 5, with 5 implying maximum problem. The questionnaire used in the study is appended in Appendix 2.

The various processes that were assessed included site selection, training of project team, site initiation, data elements, data collection, uploading, storage, usage, quality control, data safety and integrity, various related policies and agreements including publication policy, data sharing agreement and organizational structure of the project.

\section{Results}

A total of 975 patients were enrolled across all centers at the end of one year of the study (Table 1).

\section{Investigator's feedback}

The investigators rated above 8 for all questions on quality and appropriateness of the IDAPP study. The rating was higher for questions pertaining to appropriateness of design of the IDAPP study, timely and appropriate response from the central team on queries raised by the sites, quality and ease of use of web platform. All the investigators were interested in further continuation of the IDAPP study and would recommend others to join the study (Table 2). 
Table 1 Number of patients enrolled by center and in total

\begin{tabular}{lll}
\hline S. No. & Name of center & No. enrolled \\
\hline 1 & Chiang Mai University, Thailand & 83 \\
2 & Center for the Rehabilitation of the Paralysed, Bangladesh & 254 \\
3 & Spinal Injury Rehabilitation Center, Kathmandu, Nepal & 180 \\
4 & Indian Spinal Injuries Center, New Delhi, India & 202 \\
5 & National Hospital of Sri Lanka, Colombo, Sri Lanka & 16 \\
6 & University of Malaya, Kuala Lumpur, Malaysia & 70 \\
7 & Ganga Spine Injury Rehabilitation Center, Coimbatore, India & 126 \\
8 & Cheras Rehabilitation Hospital, Malaysia & 33 \\
9 & Queen Elizabeth Hospital, Malaysia & 11 \\
10 & Total & 975 \\
\hline
\end{tabular}

Table 2 Investigator's Questionnaire

\begin{tabular}{lll}
\hline Investigator's response: Part A & \\
\hline$\#$ & Question & $\begin{array}{l}\text { Median } \\
\text { [range] }\end{array}$ \\
1 & Relevance of IDAPP study & $9[8-10]$ \\
2 & Appropriateness of design of the IDAPP study & $9[8-10]$ \\
3 & Quality of documents provided for IDAPP study & $8[6-9]$ \\
4 & Quality of training provided for IDAPP study & $8[6-9]$ \\
5 & Timely and appropriate response from the & $9[8-10]$ \\
& central team on queries raised by you & \\
6 & Appropriateness of the data elements for the & $8[7-10]$ \\
& IDAPP study & $9[8-10]$ \\
7 & Quality of web platform & $9[8-10]$ \\
8 & Ease of use of web platform & Yes (all) \\
9 & Would you like to continue in the IDAPP if it is & \\
& extended further? & Yes (all) \\
10 & Would you recommend others to join IDAPP? & \\
Investigator's response: Part B & $2[1-4]$ \\
1 & Availability of internet services & $2[2-5]$ \\
2 & Time taken for data collection & $2[1-5]$ \\
3 & Availability of manpower & $2[1-3]$ \\
4 & Deficiencies in protocol including data elements & $2[1-5]$ \\
5 & Sustainability of study due to financial reasons & 2 \\
\hline & &
\end{tabular}

There were minimal problems faced by centers during the conduct of IDAPP. Availability of personnel, sustainability due to financial reasons and time taken for data collection were listed as most problematic by only one center (Table 2).

\section{Demographic details}

Demographic details are provided in Table 3. All SCI etiology-related data are provided in Table 4.
Table 3 Demographics

\begin{tabular}{|c|c|}
\hline Variable & $N\left(\%^{\mathrm{a}}\right)$ \\
\hline \multicolumn{2}{|l|}{ Gender ratio } \\
\hline Male & $790(81 \%)$ \\
\hline Female & $185(19 \%)$ \\
\hline \multicolumn{2}{|c|}{ Injury etiology } \\
\hline Fall & $513(53 \%)$ \\
\hline Transport & $374(38 \%)$ \\
\hline Assault & $31(03 \%)$ \\
\hline Sports & $14(01 \%)$ \\
\hline Others & $43(04 \%)$ \\
\hline \multicolumn{2}{|c|}{ Vertebral injury } \\
\hline Yes & $867(89 \%)$ \\
\hline No & $101(10 \%)$ \\
\hline Unknown & $7(01 \%)$ \\
\hline \multicolumn{2}{|c|}{ Associated injuries } \\
\hline Yes & $750(77 \%)$ \\
\hline No & $194(20 \%)$ \\
\hline Unknown & $31(03 \%)$ \\
\hline \multicolumn{2}{|c|}{ Neurological level of injury } \\
\hline Cervical & $430(44 \%)$ \\
\hline Thoracic & $417(43 \%)$ \\
\hline Lumbar & $99(10 \%)$ \\
\hline Unknown & $29(03 \%)$ \\
\hline \multicolumn{2}{|c|}{ Spinal surgery } \\
\hline Yes & $711(73 \%)$ \\
\hline No & $260(27 \%)$ \\
\hline Unknown & $4(<1 \%)$ \\
\hline \multicolumn{2}{|c|}{ ASIA impairment scale } \\
\hline A & $547(56 \%)$ \\
\hline B & $127(13 \%)$ \\
\hline $\mathrm{C}$ & $139(14 \%)$ \\
\hline $\mathrm{D}$ & $135(14 \%)$ \\
\hline $\mathrm{E}$ & $7(01 \%)$ \\
\hline Unknown & $20(02 \%)$ \\
\hline
\end{tabular}

${ }^{\mathrm{a}}$ Rounded to zero decimal places 
Table 4 SCI etiology-specific data

\begin{tabular}{|c|c|}
\hline Variable & $N(\%)$ \\
\hline \multicolumn{2}{|l|}{ Fall } \\
\hline \multicolumn{2}{|l|}{ Location of fall } \\
\hline At home & $287(56 \%)$ \\
\hline At work & $110(21 \%)$ \\
\hline At place of leisure & $29(06 \%)$ \\
\hline Others & $33(06 \%)$ \\
\hline Unknown & $54(11 \%)$ \\
\hline \multicolumn{2}{|l|}{ Type of fall } \\
\hline Falling from a height $1 \mathrm{~m}$ or more & $352(69 \%)$ \\
\hline Falling from a height $<1 \mathrm{~m}$ & $63(12 \%)$ \\
\hline Falling on same level & $61(12 \%)$ \\
\hline Falling from an unspecified height & $24(05 \%)$ \\
\hline Unknown & $13(02 \%)$ \\
\hline \multicolumn{2}{|l|}{ Transport } \\
\hline \multicolumn{2}{|l|}{ Transport injury event } \\
\hline Vehicle occupant: driver & $198(53 \%)$ \\
\hline Vehicle occupant: passenger & $140(38 \%)$ \\
\hline Pedestrian & $20(05 \%)$ \\
\hline Unknown and others & $15(04 \%)$ \\
\hline \multicolumn{2}{|l|}{ Vehicles involved } \\
\hline Motorized two- and three-wheeled vehicle & $177(47 \%)$ \\
\hline Light transport vehicle with four or more wheels & $117(31 \%)$ \\
\hline Bicycle and tricycle & $33(09 \%)$ \\
\hline Heavy transport vehicle & $21(06 \%)$ \\
\hline Unknown and others & $23(06 \%)$ \\
\hline Animal drawn vehicle & $3(01 \%)$ \\
\hline \multicolumn{2}{|l|}{ Use of helmet (wherever applicable) } \\
\hline No & $155(67 \%)$ \\
\hline Yes & $57(25 \%)$ \\
\hline Unknown & $19(08 \%)$ \\
\hline \multicolumn{2}{|l|}{ Use of seat restrain (wherever applicable) } \\
\hline No & $139(78 \%)$ \\
\hline Yes & $19(11 \%)$ \\
\hline Unknown & $19(11 \%)$ \\
\hline \multicolumn{2}{|l|}{ History of alcohol abuse } \\
\hline No & $833(85 \%)$ \\
\hline Yes & $58(06 \%)$ \\
\hline Unknown & $84(09 \%)$ \\
\hline
\end{tabular}

${ }^{a}$ Rounded to zero decimal places

\section{Discussion}

The study confirmed the relevance of the IDAPP, the appropriateness of design as well as data elements and ease of use of web platform. The quality of document, appropriateness of training provided and support by central team was confirmed by the study. All the centers completed the data variables for patients enrolled in the study. There was
Table 5 IDAPP budget

\begin{tabular}{lll}
\hline S. No. & Item head & Cost in USD \\
\hline 1 & Development of web platform & 900 \\
2 & Annual maintenance of web platform & 130 \\
3 & Onetime payment for 9 centers & 6750 \\
4 & Total & 7780 \\
\hline
\end{tabular}

no particular data variable which was highlighted by any center as difficult to capture. Though one investigator identified the availability of personnel and financial constraints as major limiting factors for sustainability of such a study, the relevance of the study and its importance in continuity has been confirmed by their willingness to continue and to recommend other centers to join in this endeavor. Thus, the pilot study has established the feasibility of a larger global database. Feedback also suggests that for a larger study, adding non-traumatic SCI data variables should be considered in the future.

The ISCoS global mapping project had highlighted the paucity of data from LMICs. One factor could be financial implications in collecting the data. In an Australian study, it has been cited that the expense of collecting long term outcome statistics at a solitary point for 2000 major trauma patients is estimated at AUD 30,000 (USD 23760) [9]. In a proposed Australian budget to collect SCI data [10], it's estimated to cost AUD 1,78,456 (USD 141337) to collect solitary data for 975 patients (the number of patients data has been provided through this study). In comparison, the cost of one year IDAPP study, including administrative and maintenance cost (per year), was USD 7780, with USD 7650 \& USD 130 being non recurring and recurring components respectively (Table 5). It may be noted that this would be the cost for ongoing data collection as against the cost for data collection at a single time point in the Australian study. However, data collection was done voluntarily at all participating centers. The IDAPP has thus provided a low-cost solution to creation of a data repository in such countries.

Understanding the epidemiology of SCI in a region could help in directing the resources for appropriate prevention strategies. Also, this could direct the sparse resources in most appropriate manner for SCI care and rehabilitation.

For any epidemiological study, it is important to analyze details on unknown and missing data. Since sites could not upload data to the central database till all the data elements are filled in, they had the option for selecting the option of 'unknown'. Other than 'location of fall', 'use of helmet or seat restraint' and 'history of alcohol abuse' where the 'unknown' option was ticked for 11, 11 and 9\% of patients respectively, 'unknown' option was selected in less than $4 \%$ of patients for all other data elements. Voluntary disclosure 
and unclear mechanism of injury could be the reason for high 'unknown' option for these data elements.

The identified centers across the region varied from acute hospitals to specialized spinal injury centers and from government institutes to semi-government, nongovernmental organizations (NGOs) to private centers. This variance in the nature of participating centers was provisioned with a view to help broaden and identify potential challenges for the subsequent project in which multiple centers across the globe would be involved.

As per the WHO report in 2013 [11], males are more commonly affected by SCI than females. The same has been reflected in our study as well, as $81 \%$ of enrolled patients were male. There are many international studies which report the most common cause of SCI as road traffic crashes [3]. This is especially true for high-income or developed countries. However, some recent studies in South East Asian countries have reported fall as the most common cause of SCI in the region [12]. The IDAPP study further supports this observation with falls accounting for $53 \%$ of SCI in this patient population as compared to $38 \%$ by transport-related injuries. However, transport related injuries were the most common cause of SCI in the study in two of the participating countries, Thailand and Malaysia. This is in line with the reported commonest cause of SCI in these countries $[13,14]$.

In the study, $89 \%$ patients had vertebral injuries and $73 \%$ patients underwent spinal surgery. One study from US has reported surgeries in a lower percentage $(65 \%)$ of patients with SCI [15]. The fact that the IDAPP study was conducted in mainly tertiary centers of each country could be the reason for high percentage of spinal surgeries conducted on these patients.

Of all SCI enrolled in the study, 56\% $(n=547)$ were complete injuries (AIS-A), whereas 41\% $(n=401)$ were incomplete SCI (AIS-B, C and D). Statistics from developed countries show a higher percentage of incomplete SCI [16]. Higher incidence of high falls and/or inappropriate pre-hospital care including improper rescue techniques from accident sites due to lack of knowledge, as prevalent in the region [17] may be the reason for the higher percentage of complete injuries, as reported in the IDAPP study. Also, it has been noted that vehicles are less safe in low and middle income countries (LMICs), with non-availability of seat belts, air bags and child restraints in many vehicles [18]. The use of these mechanisms in the vehicle could be an important factor preventing injuries after any accident [19].

Studies from India, China and Thailand have reported a higher percentage of the spinal injured to be paraplegics $[12,20]$, as compared to tetraplegics in US and other developed countries [20, 21]. In our study also, the percentage of patients with paraplegia was higher. However, the percentage of patients with cervical level of neurological injury is increasing with time in the region [12].

High fall (fall from more than $1 \mathrm{~m}$ ) is the most common cause of SCI in the region. In developed countries low falls (fall from a height of $<1 \mathrm{~m}$ ) are more common [22]. In this study the high falls accounted for $69 \%$ of the falls. Fall from $<1 \mathrm{~m}$ height and from the same level were reported to be about $12 \%$ each. The remaining $7 \%$ of falls were from unspecified or unknown height. The most common site of fall was at home (56\%), whereas, $21 \%$ falls took place at the work place. However, in contrast to our report, the global report on fall epidemiology recorded $56 \%$ of fall incidence happening outside the home [23].

Most $(91 \%)$ of the transport related injuries occurred to the vehicle occupant i.e., driver or passenger of the vehicle. Pedestrians were involved in only $5 \%$ of the cases, though a study on road traffic crashes (RTCs) in the region has noted a slightly high percentage of involvement of pedestrians in RTCs (13.4\%) [24]. The most common type of vehicle available in the region is a motorized two or three wheeled vehicle [24] and it was involved in $47 \%$ of the cases, followed by light transport vehicle of four or more wheels. The data is comparable to other studies from the region [25]. Despite the regulation of compulsory use of helmet for two/ three wheeled vehicles, they were hardly used by the patients involved in RTCs $(67 \%)$. Similarly, seat restraints were not in place in $78 \%$ of patients involved in RTCs involving light and heavy transport vehicles. Regulations of helmet as well as seat restraint use and their proper implementation could be one of the SCI prevention strategies. Another unique cause of SCI is the injury to women riders of two/three-wheeled motorized vehicle due to headgear (scarves which the women in the region often wear) getting entangled in the rear wheel resulting in a fall. A campaign to highlight the use of helmet and proper use of headgear may help prevent SCI due to these causes in the region.

In contrast to other studies, where up to $20 \%$ of victims involved in road traffic crashes have evidence of alcohol in their blood, only $6 \%$ of this patient population had evidence of concomitant alcohol or psychoactive drug/substance use [26]. This may be due to the voluntary reporting used in the study.

The project had limitations inherent to a center-based pilot study. The data may not be appropriately representative of the region since it was a center based study with a limited sample size. Another limitation of the study was that the time required for data collection and entry for each patient was not documented. 


\section{Conclusions}

IDAPP has provided a low-cost solution to creation of a data repository in LMIC. There were no major anomalies reported for the study processes. The appropriateness of the data base variables and quality and ease of use of web platform has been confirmed. Thus, a larger global database is feasible, economical and practical. Expansion to other centers/regions and including non-traumatic SCI would be the next step forward.

The study also provides demographic and safety data of SCI patients from 9 centers in the South East Asia region. High falls is the most common cause of SCI and a higher percentage of SCI are paraplegics and complete (AIS-A) in the region in contrast to other high income countries (HICs).

Acknowledgements We acknowledge the contributions of the Advisory Committee members including Bonne Lee, Michael Fitzharris, David Berlowitz, Fin Biering Sorensen, Marcel Post, Vanessa Noonan, James Middleton, Herndon Murray, Raymond Cripps, and Yuying Chen in conceptualization (including finalizing the Minimal Safety Data Set) and implementation of the project. Their contribution towards the finalization of this manuscript is also acknowledged.

\section{Compliance with ethical standards}

Conflict of interest The authors declare that they have no conflict of interest.

\section{References}

1. Oderud T. Surviving spinal cord injury in low income countries. Afr J Disabil. 2014;3:1-9.

2. Allotey P, Reidpath D, Kouamé A, Cummins R. The DALY, context and the determinants of the severity of disease: an exploratory comparison of paraplegia in Australia and Cameroon. Soc Sci Med. 2003;57:949-58.

3. National Spinal Cord Injury Statistical Center, Facts and Figures At a Glance. Birmingham, AL: University of Alabama at Birmingham, March 2013.

4. Mohan D, Tiwari G, Khayesi M, Nafukho FM. Road traffic injury prevention: Training manual. Geneva, Delhi: World Health Organization, Indian Institute of Technology; 2006.

5. Singh NJ, Kartha GSC, Chandwani K, Patanker PG, Bhardwaj, SA. Evaluation of Road Accident costs, Research Digest, Indian highways, 28, 2000.

6. Lee BB, Cripps RA, Fitzharris M, Wing PC. The global map for traumatic spinal cord injury epidemiology: update 2011, global incidence rate. Spinal Cord. 2014;52:110-6.

7. DeVivo M, Biering-Sørensen F, Charlifue S, Noonan V, Post M, Stripling T. et al. International Spinal Cord Injury Core Data Set. Spinal Cord. 2006;44:535-40.

8. World Health Organization. International Classification of External Causes of Injury (ICECI). Geneva: WHO; 2003.
9. Gabbe BJ, Sutherland AM, Hart MJ, Cameron PA. Populationbased capture of long-term functional and quality of life outcomes after major trauma: the experiences of the Victorian State Trauma Registry. J Trauma Acute Care Surg. 2010;69:532-6.

10. Gosling C, Gabbe B, Jennings P, Cameron P. Scoping study to enhance spinal cord injury data connectivity within Australia and internationally: Phase one report. Spinal Cord Injury Network: Sydney.

11. WHO. Spinal cord injury, Fact sheet. November 2013. http://www.who.int/mediacentre/factsheets/fs384/en/ Accessed 29 April 2017.

12. Chhabra HS, Arora M. Demographic profile of traumatic spinal cord injuries admitted at Indian Spinal Injuries Centre with special emphasis on mode of injury: a retrospective study. Spinal Cord. 2012;50:745-54.

13. Ibrahim A, Lee KY, Kanoo LL, Tan CH, Hamid MA, Hamedon NM, et al. Epidemiology of spinal cord injury in Hospital Kuala Lumpur. Spine. 2013;38:419-24.

14. Pajareya K. Traumatic spinal cord injuries in Thailand: an epidemiologic study in Siriraj Hospital, 1989-1994. Spinal Cord. 1996;34:608-10.

15. Tator $\mathrm{CH}$, Fehlings MG, Thorpe K, Taylor W. Current use and timing of spinal surgery for management of acute spinal surgery for management of acute spinal cord injury in North America: results of a retrospective multicenter study. J Neurosurg. 1999;91:12-8.

16. National Spinal Cord Injury Statistical Center, Facts and Figures at a Glance. Birmingham, AL: University of Alabama at Birmingham, February 2014.

17. Rathore MF, Rashid P, Butt AW, Malik AA, Gill ZA, Haig AJ. Epidemiology of spinal cord injuries in the 2005 Pakistan earthquake. Spinal Cord. 2007;45:658-63.

18. Skolnik R. Essentials of global health. Sudbury, MA: Jones \& Bartlett Publishers; 2008.

19. WHO. Need for seat-belts and child restrains. Road safety manual. http://www.who.int/roadsafety/projects/manuals/seatbelt/seat_ belt_manual_module_1.pdf Accessed 29 Apr 2017.

20. Ning GZ, Wu Q, Li YL, Feng SQ. Epidemiology of traumatic spinal cord injury in. Asia: a Syst Rev J Spinal Cord Med. 2012;35:229-39.

21. Hagen EM, Rekand T, Gilhus NE, Grønning M. Traumatic spinal cord injuries-incidence, mechanisms and course. Tidsskr Den Nor Laege: Tidsskr Prakt Med, Ny raekke. 2012;132:831-7.

22. World Health Organization. Ageing, and Life Course Unit. WHO global report on falls prevention in older age. World Health Organization, 2008. http://www.who.int/ageing/publications/Fa lls_prevention7March.pdf Accessed 29 Apr 2017.

23. Yoshida-Intern S. A global report on falls prevention epidemiology of falls. Geneva: WHO; 2007.

24. REGION SE. Road safety in the South-East Asia Region 2015. http://www.who.int/violence_injury_prevention/road_safety_sta tus/2015/Road_Safety_SEAR_3_for_web.pdf Accessed 29 Apr 2017.

25. Patil SS, Kakade RV, Durgawale PM, Kakade SV. Pattern of road traffic injuries: a study from western Maharashtra. Indian J Community Med. 2008;33:56.

26. Baruah AM, Chaliha R. A study of incidence of alcohol use in fatal road traffic accidents. J Indian Acad Forensic Med. 2015;37:12-5. 